\title{
Unbalanced Low-Level Jet and Solenoidal Circulation Associated with Heavy Rainfalls
}

\author{
By Seiichi Matsumoto \\ Fukuoka District Meteorological Observatory, Fukuoka, Japan. \\ (Mannuscript received 2 September 1971, in revised form 20 January 1972)
}

\begin{abstract}
A southerly low-level jet appeared over Kyushu on July 7, 1970 when a large amount of precipitation was observed to the west of jet axis. The mesoscale thermal structure around the jet core shows an indirect indication of adjustment with the wind field but it is found to be highly unbalanced. The warmer area appearing below the jet core to the east is characterized by dryness, which is possibly generated by an indirect solenoidal circulation.

Similar relationship among wind, temperature and relative humidity field is found in the lower troposphere even for the monthly mean values of June 1970.
\end{abstract}

\section{Introduction}

Among characteristic features of the atmospheric motion, momentum concentration in a form of jet stream is a most remarkable phenomenon. Understanding of generation, maintenance, structure etc. of the westerly jet stream at tropopause level and its role on atmospheric phenomena has been a central problem of the modern meteorology especially for large scale behaviors.

Soon after the discovery of jet stream in the upper atmosphere, it was found that the momentum can concentrate in the lower troposphere and the notion of low-level jet is becoming popular. But there are some confusions due to the lack of its definition such as that given by WMO for large scale motions. It seems obvious that there are at least two kinds of low-level jet, one which appears in the lowermost layer next to the ground surface and shows a remarkable diurnal variation (Wexler, 1971), and the other which appears in the layer between about $600 \mathrm{mb}$ and $900 \mathrm{mb}$ level. The former is undoubtedly related to the planetary boundary layer problem. Synoptic meteorologists are interested rather in the latter because it is deeply related to severe phenomena such as heavy rainfall, heavy snowfall, tornado etc. (Beebe and Bates, 1955).

The author has pointed out the importance of the second type of the low-level jet in his recent studies on severe rainstorms (Matsumoto, Yoshizumi and Takeuchi, 1970: Matsumoto, Ninomiya and Yoshizumi, 1971). The low-level jet is undoubtedly a smaller scale phenomenon and little is known about its structure and mechanism simply because of the lack of adequate observations. Finer scale observations are revealing finer structures and Matsumoto and Ninomiya (1971) showed a mesoscale structure of a low-level jet.

It is quite important to study in detail the structure and the dynamics of this lower atmospheric behavior not only because it will develop forecasting techniques of severe rainstorms but because it is inevitable to know mesoscale characters to improve atmospheric models.

Basing on the data of the Severe Rainstorm Research Project observation of 1970, further detailed analyses are made on the low-level jet which appeared in the midst of observing network on July 7,1970 . The temperature and the relative humidity distribution around the jet core seem to support the circulation model as suggested in the authors previous paper (Matsumoto and Ninomiya, 1971).

\section{Weather situation on July 7,1970}

The $700 \mathrm{mb}$ chart at 21 LST July 7, 1970 provided by JMA is reproduced in Fig. 1. Height contours (full lines) and isotherms (dashed lines) show that a rather small cut-off cold vortex is located to the west of the Kyushu Island, and 


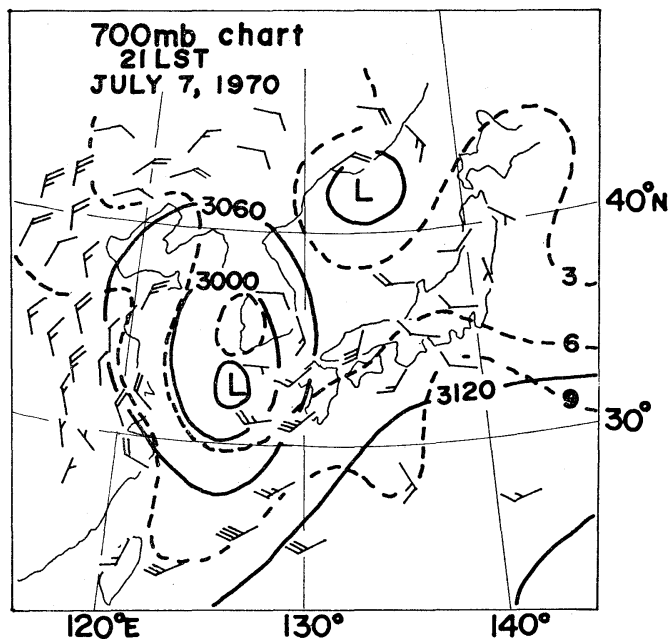

Fig. 1. $700 \mathrm{mb}$ chart at 21 LST July 7, 1970.

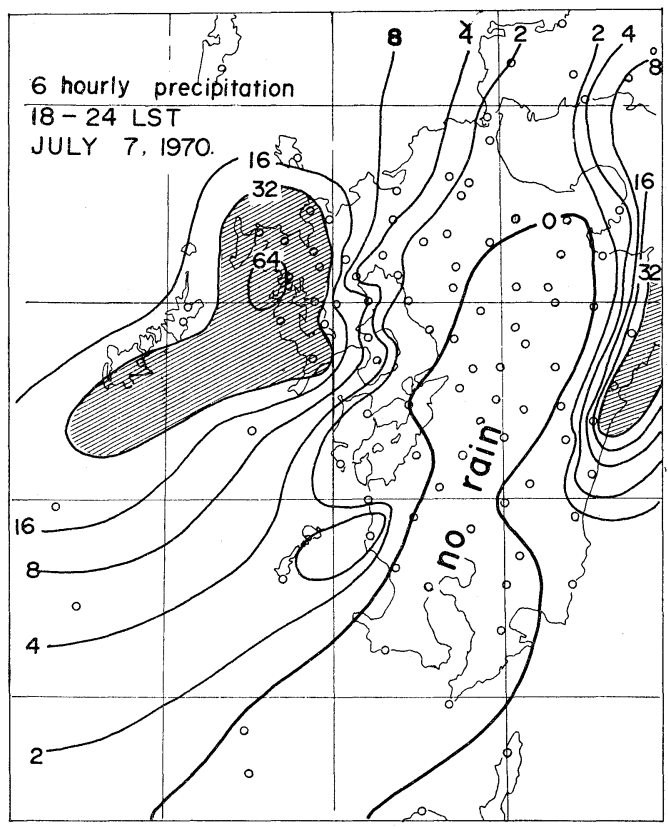

Fig. 2. Six-hourly precipitation during the period 18-24 LST July 7, 1970. Circles indicate rainguage stations over the Kyushu District.

southerly winds are prevailing over the southwestern part of Japan.

Fig. 2 shows six-hourly precipitation over the Kyushu District during the period centered around the map time. It is seen clearly that a pretty large amount of rainfall is observed along the western and eastern coast of the Kyushu Island. It is rather surprising that any of preci-

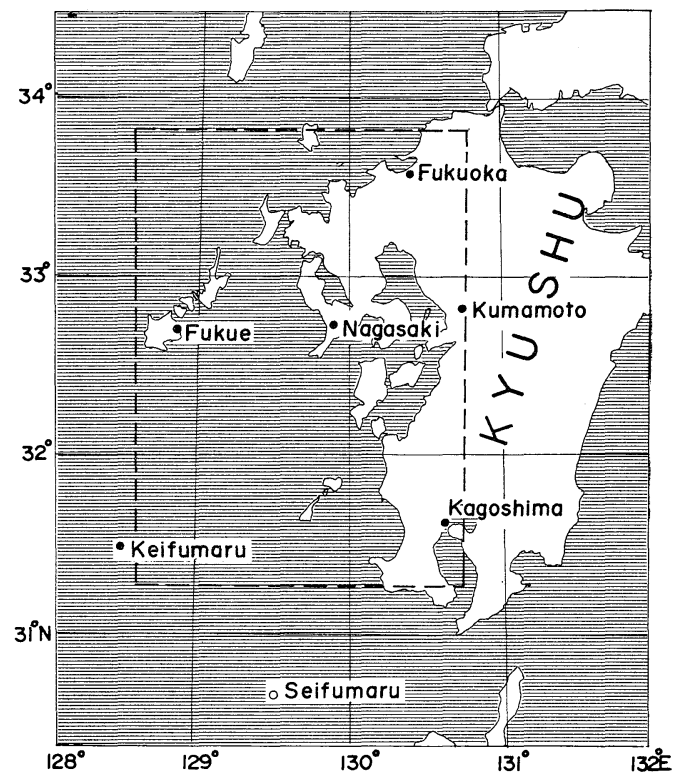

Fig. 3. Aerological network over the Kyushu District. Black and white circles are rawin-sonde and radio-sonde stations respectively. Square area surrounded by dashed line is for computation of divergence field.

pitation did not take place at all over the mountaineous region. Thus the rainfall pattern shows up a remarkable alignment towards north-northeastward direction which agrees with the upper air current. Raingauge stations are distributed over sea area because there are several small island stations and also JMA meteorological observation ships, Keifumaru, Chofumaru and Seifumaru were making fixed point observation for the Project.

In the following sections, let us see three dimensional atmospheric structure at 21 LST July 7, 1970. Fig. 3 shows mesoscale aerological network set up by the Project during the period from July 5 to July 12, 1970. Black circles and a white circle indicate rawin-sonde stations (including routine stations at Fukuoka and Kagoshima) and a radio-sonde station. The distance between stations is about $100 \mathrm{~km}$.

\section{Characteristic wind, temperature and moisture distribution in the lower troposphere}

During the Project observation period, threehourly rawin-sonde soundings were taken at Nagasaki and Kumamoto (see Fig. 3 for locations). Fig. 4 is the time section of soundings taken at 


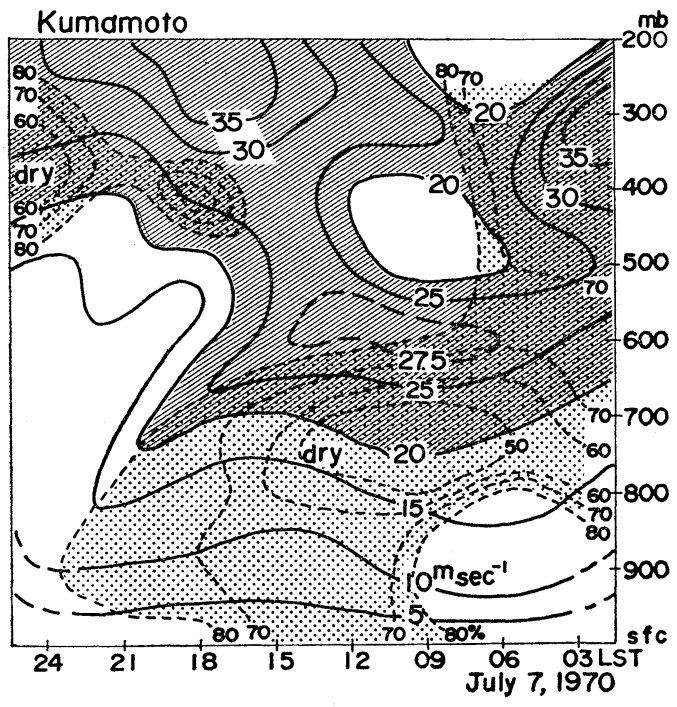

Fig. 4. Time section of wind and relative humidity field at Kumamoto. Full lines are isotach labeled in $\mathrm{m} \mathrm{sec}^{-1}$ (wind speed larger than $20 \mathrm{~m} \mathrm{sec}^{-1}$ shaded), dotted lines are isolines of relative humidity labelled in $\%$ (dry area with less than $80 \%$ stippled).

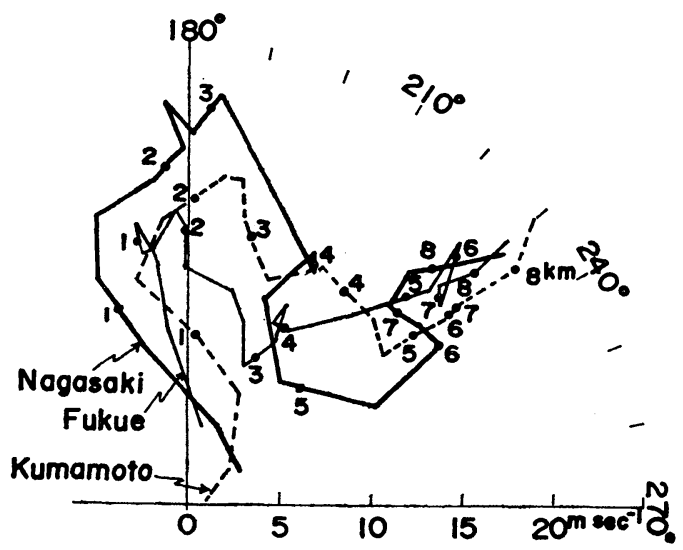

Fig. 5. Wind hodograph at 21 LST July 7, 1970 at Nagasaki (heavy solid line), at Kumamoto (dashed line) and at Fukue (thin solid line) labelled with height in $\mathrm{km}$.

Kumamoto for the one day period on July 7, 1970. Isotachs are given by heavy lines and shaded area indicates strong wind of more than $20 \mathrm{~m} \mathrm{sec}^{-1}$. We can find a momentum concentration in the lower troposphere below $500 \mathrm{mb}$ level. This is a manifestation of low-level jet. The relative humidity field is presented by dotted

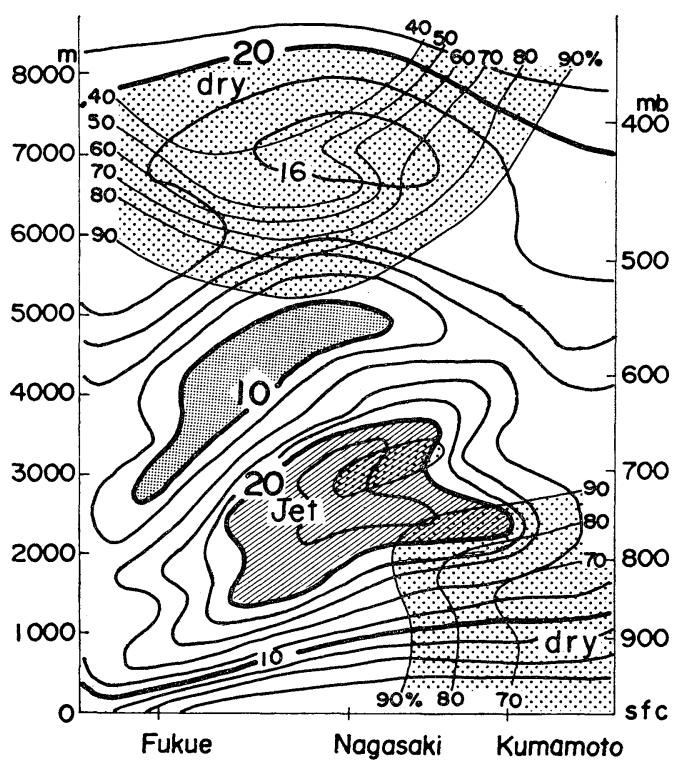

Fig. 6. Vertical cross section of wind speed (heavy lines) and relative humidity (thin lines) along the zonal plane through Fukue to Kumamoto, at 21 LST July 7, 1970. Wind maximum and minimum are hatched and shaded respectively. The dry areas with less than $90 \%$ of relative humidity are stippled.

lines. Dry area appears below low level wind maximum in earlier time and above it in later time. Since the time section can represent horizontal distribution when the system moves without significant changes, we can infer to some extent the characteristic structure of moisture around low-level jet.

Since the prevailing wind in the lower troposphere is southerly, east-west cross section will give us lateral distribution. Kumamoto, Nagasaki and Fukue are located on almost the same latitude from east to west with intervals of $80 \mathrm{~km}$ and $100 \mathrm{~km}$. Wind hodographs at those stations are given in Fig. 5. The height is labeled in $\mathrm{km}$ unit on each one. It is found clearly that there are two separate wind systems, south-westerly in the upper troposphere and southerly in the lower troposphere. The low-level jet under question is the latter. Jet axis runs through Nagasaki as seen from the heavy line in Fig. 5.

The east-west cross section is given in Fig. 6, where isotachs and isolines of relative humidity are given by heavy lines and thin lines respec- 


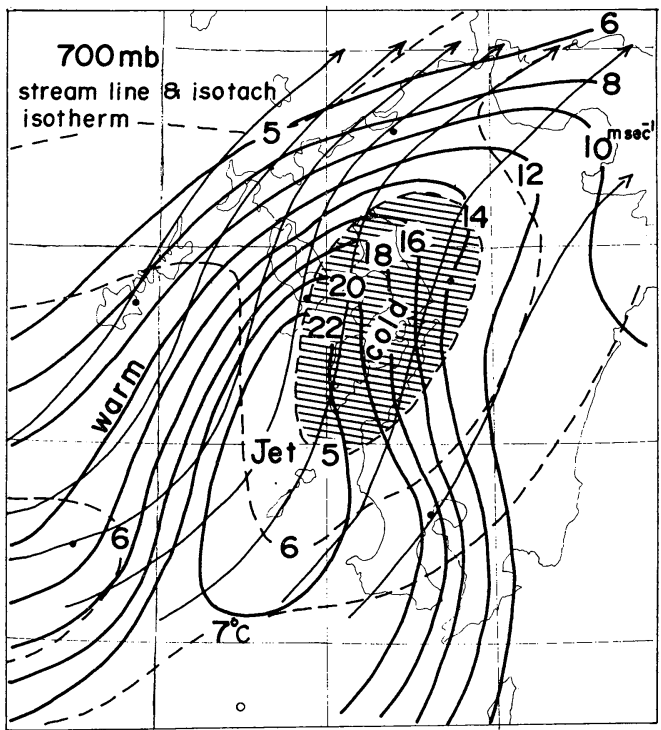

Fig. 7. Stream line and isotach at $700 \mathrm{mb}$ surface are given by thin solid lines and heavy solid lines labeled in $\mathrm{m}$ $\mathrm{sec}^{-1}$ respectively. Isotherms are also entered by dashed lines labeled in ${ }^{\circ} \mathrm{C}$. Cold area are shaded.

tively. There appears a remarkable low-level jet core over Nagasaki at about $700 \mathrm{mb}$ level (see the hatched area in Fig. 6). Another noticeable feature in the wind field is the existence of wind minimum above the low-level jet core with wind speed less than $10 \mathrm{~m} \mathrm{sec}^{-1}$ as indicated by the shaded area in Fig. 6. The magnitude of vertical wind shear both below and above the jet core amounts to a very large value more than $10 \mathrm{~m} \mathrm{sec}^{-1} / 100 \mathrm{mb}$. Also the horizontal wind shear of both side has large magnitude of more than $2 \times 10^{-4} \mathrm{sec}^{-1}$.

It should be emphasized that we can find dry areas to the lower right and to the upper left of the jet core facing downstream. This fact strongly suggests circulations in the lower and the upper layer with opposite sence. It is also pointed out from Fig. 2 that precipitation took place only in the positive vorticity side of the jet core, showing that the area corresponds to the up current branch of the circulation. Beebe and Bates (1955) suggested that the tornado occurence is limited in the positive vorticity side of low-level jets also.

Detailed upper air analyses are made using the project observations, and mesoscale fields within the area surrounded by dashed line in Fig. 3 will be discussed in the next section. Wind field

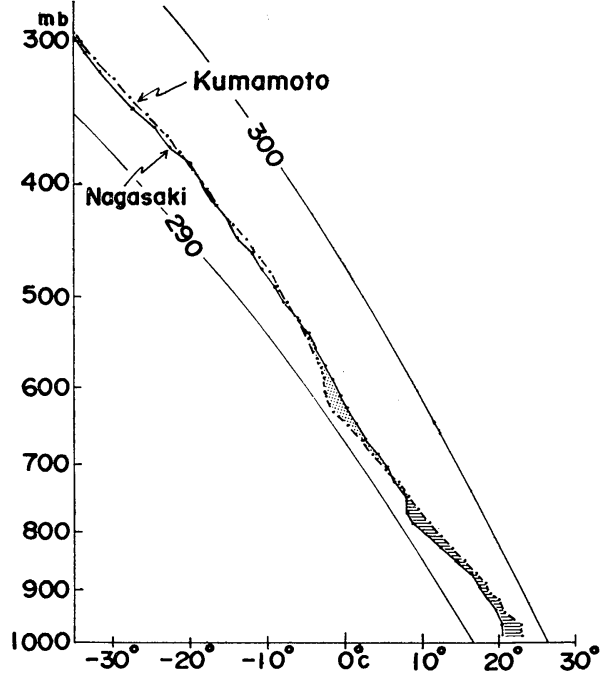

Fig. 8. Ascent curves at Nagasaki (solid line) and Kumamoto (dashed line) at 21 LST July 7, 1960. Moist adiabats are entered.

at $700 \mathrm{mb}$ level also is given in Fig. 7, where stream lines and isotachs are given by thin line arrows and heavy solid lines respectively. It is clear that general southwesterly flow turns to southerly over the Kyushu District and creates a remarkable momentum concentration along western coast of Kyushu. The maximum wind speed is estimated to be as much as $22 \mathrm{~m} \mathrm{sec}^{-1}$ or more. There are many other cases in which we observe maximum wind of more than $25 \mathrm{~m}$ $\sec ^{-1}$ at this level under severe rainfall situations.

Isotherms at $700 \mathrm{mb}$ level are also entered in Fig. 7 by dashed line, and cold area is hatched. Those show detailed structure embedded in the synoptic field presented in Fig. 1. Cold air is found to the right (east) of the jet core. There exists a temperature gradient from west to east across the jet core, which requires negative wind shear above under the thermal wind relationship. This is actually the case, but quantitatively much more larger negative wind shear is observed. Let us discuss the thermal wind balance in the following sections.

Vertical temperature distribution over Nagasaki and Kumamoto are given in Fig. 8 by solid line and broken line respectively. The temperature difference between Nagasaki and Kumamoto located near the jet core and to the east respectively is negative below and positive above the $700 \mathrm{mb}$ level, the wind maximum level. Maxi- 
mum difference is approximately $2^{\circ} \mathrm{C}$ both below and above. Moist adiabats are entered in this figure for reference. It is seen that the lower layer is conditionally unstable and the upper layer stable, and the horizontal temperature gradient is reversed corresponding to the reversed vertical wind shear below and above the jet core.

\section{Three dimensional structure of the low-level jet}

The observational data of the mesoscale network of Severe Rainstorm Research Project allows us to make detailed three dimensional analyses which might not be expected without it.

Fig. 9 shows schematically a panoramic view of the wind field at 21 LST July 7, 1970. Isotach fields on 600,700 and $800 \mathrm{mb}$ level are shown simultaneously. Areas of momentum concentration are hatched for wind speed larger than $18 \mathrm{~m} \mathrm{sec}^{-1}$. Most important feature appearing here is that the maximum wind is found to the upstream side in higher levels. In other words the air with larger momentum tails down to the

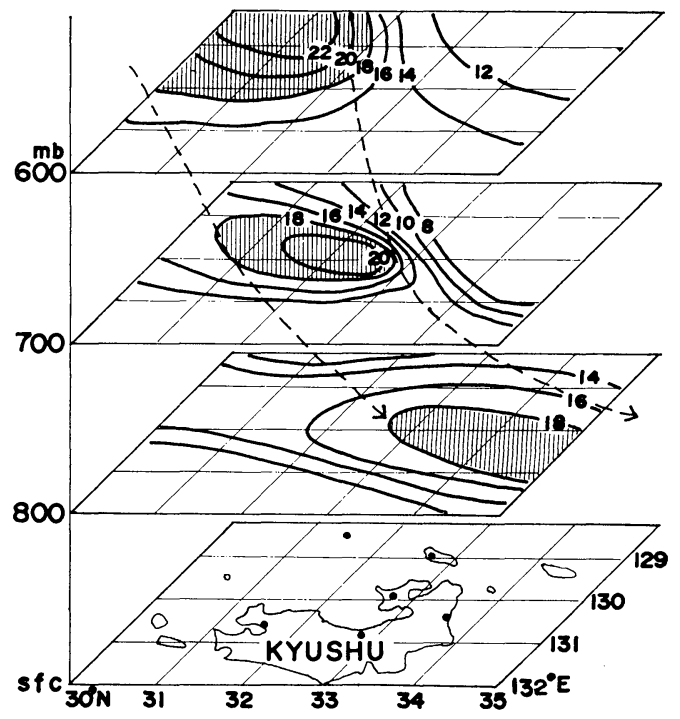

Fig. 9 Panoramic view of isotach fields at 600,700 and $800 \mathrm{mb}$ levels. Dashed lines connect areas of larger momentum.

\section{$\omega_{600}$ unit in $10^{-2} \mathrm{mb} \mathrm{sec}{ }^{-1}$}

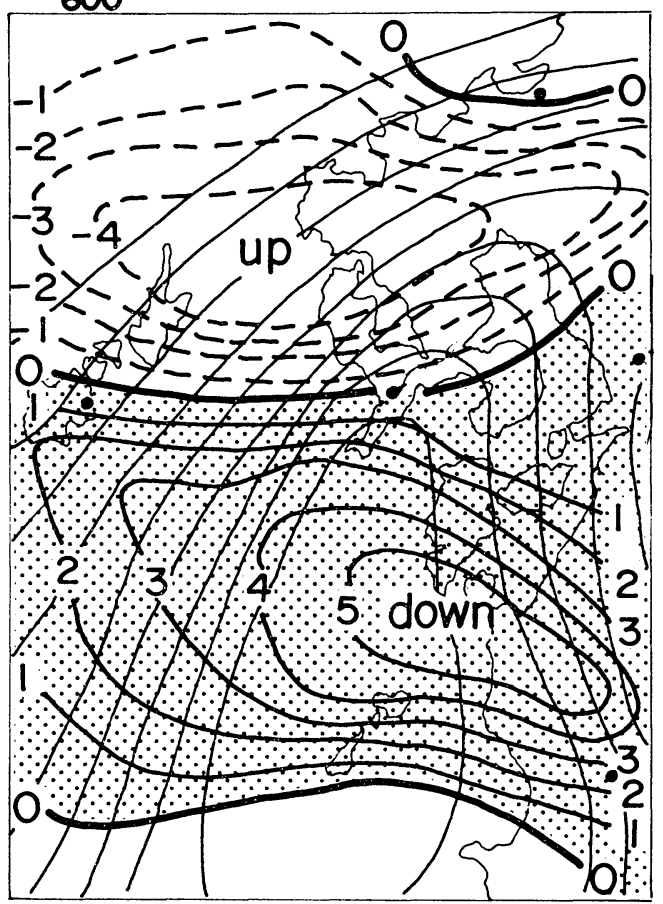

div 900 unit in $10^{-4} \sec ^{-1}$

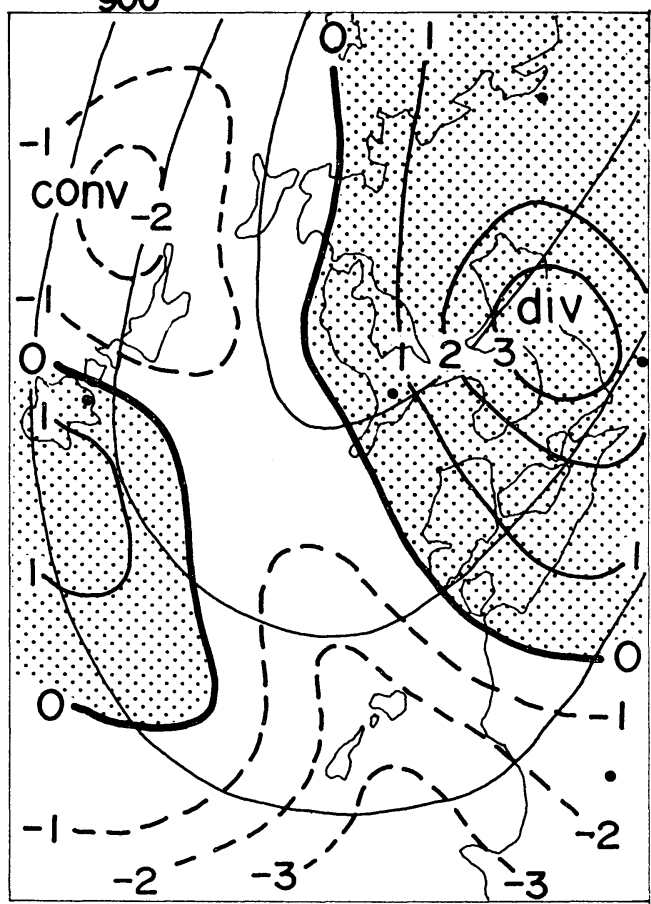

Fig. 10. Left figure: vertical motion field at $600 \mathrm{mb}$ level (shaded areas for downward motion) together with isotachs at $700 \mathrm{mb}$ level. Right figure: divergence field at $900 \mathrm{mb}$ level (shaded areas for divergence) together with isotachs at $800 \mathrm{mb}$ level. See fig. 3 for computation domain. 
downstream as indicated by dashed lines.

The fact mentioned above will make a suggestion on the generation of low-level jet stream. Matsumoto, Ninomiya and Akiyama (1967) proposed a hypothesis that the downward momentum flux due to convective activity homogenizes the wind speed within convective layer. This seems plausible since we often observe fairly uniform wind profile over heavily precipitating and therefore highly convective area. However we sometimes find out pronounced wind maximum in the lower layer. The case we are dealing here is a typical example (see Fig. 6 and Fig. 11). Then a question arises where this strong momentum comes from. It may be rather difficult to assume that the downward momentum transfer be kept against counter gradient. Another possibility is that the larger momentum in the upper layer of highly baroclinic atmosphere is carried down by an organized downward motion as shown by the dashed lines in Fig. 9.

The divergence and the vertical motion field are analysed in the square area given in Fig. 3 by dashed line, based on the interpolated mesoscale $u$ and $v$ field. In the left-hand side figure of Fig. 10 is shown $\omega$ distribution at $600 \mathrm{mb}$ level together with the isotachs at $700 \mathrm{mb}$ level. The downward motion area is shaded. We can assertain the existence of downward current above the jet core. The magnitude amounts to as much as $5 \times 10^{-2} \mathrm{mb} \mathrm{sec}^{-1}$, which is large enough to bring down air parcels by the depth of $100 \mathrm{mb}$ within $30 \mathrm{~min}$.

The right-hand side of Fig. 10 gives the divergence field at $900 \mathrm{mb}$ level together with isotachs at $800 \mathrm{mb}$ level. The shaded area showing divergence is found to the east of low-level jet core and convergence to the west. The divergence is of the order of $10^{-4} \mathrm{sec}^{-1}$ which characterizes mesoscale phenomena. The fact that divergence and convergence are distributed anti-symmetrically against the axis of low-level jet core clearly indicate circulation in the layer below the jet stream as was suggested by Matsumoto and Ninomiya (1971). Features in the upper layers are obscured probably because of the poorness of accuracy and density of observations.

\section{Solenoidal circulation around the unbalanced low-level jet}

We have already seen that warm and dry air occupies the laver to the right (east) under the

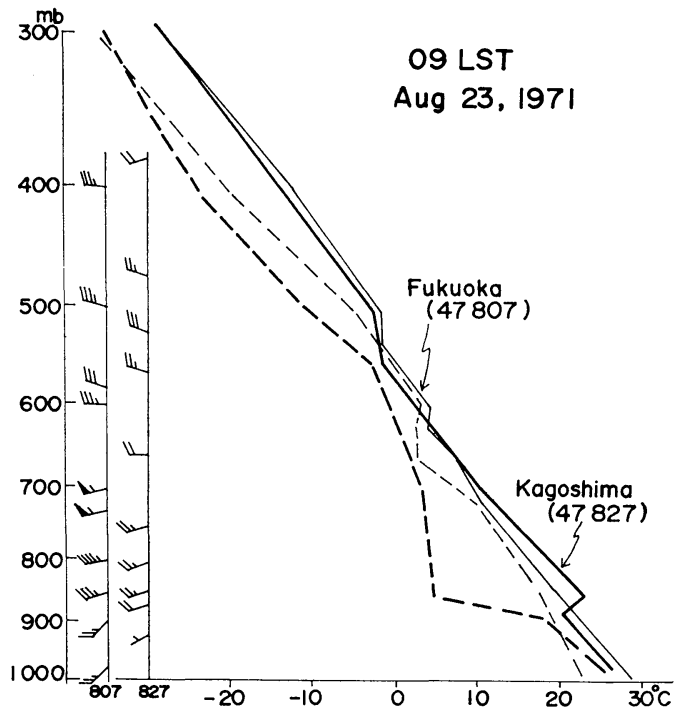

Fig. 11. A typical soundings taken at Kagoshima (47807) and Fukuoka (47827) at 09 LST Aug. 23, 1971. Temperature and dew point temperature are shown by solid lines and dashed lines respectively. Wind barbs are given in the left hand side.

low-level jet. This area coincides with the strong divergence and therefore the downdraft region. Thus it is obvious that this dry and warm air is built up by the downdraft branch of circulation. On the other hand, the updraft branch region coincides with rain area as seen in Fig. 2. In the layer above the jet level, the situation is almost reversed.

There are many observations showing the extreme dry area in the region around low-level jet stream. In order to define its location relative to the jet core, the word left or right will be used hereafter facing downstream along the jet axis. It is quite often that we observe extreme dryness in the upper left (see e.g. Matsumoto and Ninomiya, 1971). On the other hand the dryness in the lower right also is revealed on some occasions by upper-air soundings. The case on August 23, 1971 is a typical example, and the ascent curve at Kagoshima located to the south of westerly low-level jet is given in Fig. 11. Furthermore we can point out that extremely warm and dry weather is sometimes experienced to the south of severe rainfall region (for example the Kanto District was very warm and dry at the time of "Uetsu heavy rainfall" in 1969).

Now let us consider the mechanism of circula- 


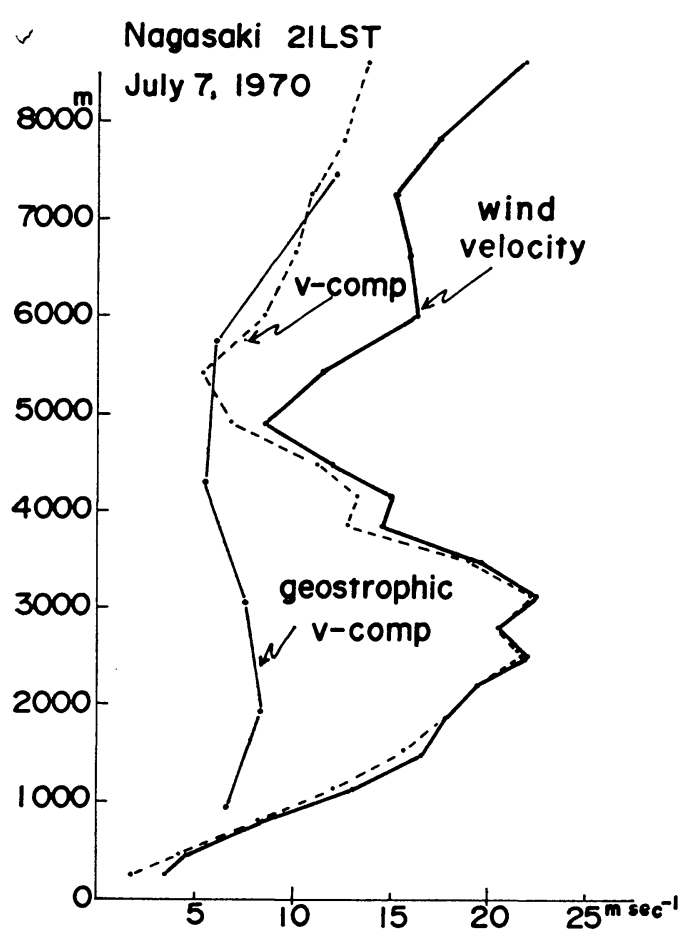

Fig. 12. Wind profile at Nagasaki. North-south components of actual wind and geostrophic wind are entered by dotted line and thinner line respectively.

tion in relation to low-level jet streams. Fig. 12 shows wind profile at 21 LST July 7, 1970. Total wind speed is given by heavy line and we can see wind maximum at $3000 \mathrm{~m}$ level (approximately $700 \mathrm{mb}$ level) with a wind speed of $22 \mathrm{~m} \mathrm{sec}^{-1}$ which is about equal to the wind speed at $300 \mathrm{mb}$ level. As was shown previously that the low-level jet is southerly in this particular occasion, the southerly wind component is given by dotted line in Fig. 12. The southerly component of geostrophic wind is computed from the geopotential height difference between Kumamoto and Fukue, and is given by thin solid line in Fig. 12. It should be emphasized that the wind in the lower troposphere below $500 \mathrm{mb}$ level is found to be highly non-geostrophic. The geostrophic wind is less than one half of the actual wind. The author (Matsumoto, Fujita and Asai, 1962) showed previously that a remarkable southerly low-level jet was observed at the time of the severe rainfalls in June 1961 and it was super-geostrophic. The super-geostrophic low-level jet comes out even in the averaged wind field over several days (Matsumoto, Yoshizumi and Takeuchi, 1970:

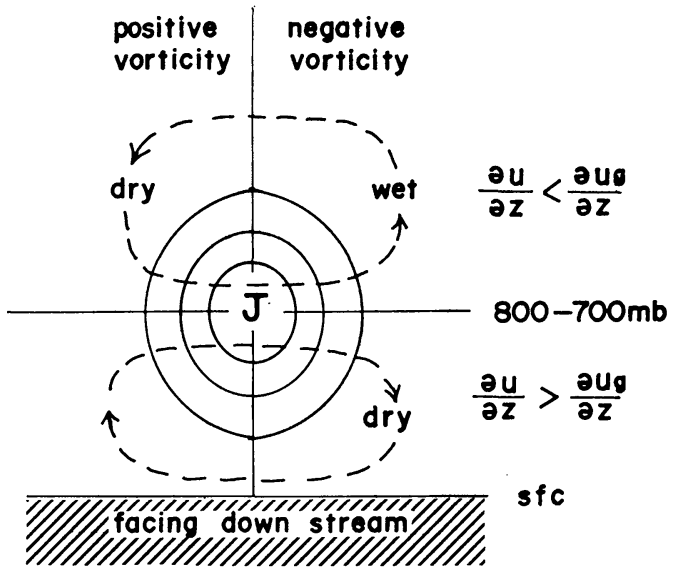

Fig. 13. Circulation model around an unbalanced low-level jet.

Matsumoto, Ninomiya and Yoshizumi, 1971). The fact that also the geostrophic wind assumes maximum value at about the same level as the low-level jet is linked with the characteristic temperature distribution mentioned above through thermal wind relationship. The temperature gradient between warm air and cold air found on both side of the jet axis is reversed from below to above the jet level, but the magnitude of the geostrophic wind shear $\frac{\partial v_{g}}{\partial z}$ is much smaller than that of the actual wind shear $\frac{\partial v}{\partial z}$. Thus we have the following conditions:

$$
\begin{aligned}
& \frac{\partial v}{\partial z}>\frac{\partial v_{g}}{\partial z} \text { below the jet level, } \\
& \frac{\partial v}{\partial z}<\frac{\partial v_{g}}{\partial z} \text { above the jet level. }
\end{aligned}
$$

The unbalanced situation should generate solenoidal circulation. The relevant dynamical equation is the vorticity equation along the jet axis i.e.

$$
\begin{aligned}
& \frac{d \eta}{d t}+D_{z x} \gamma_{j}+v_{z} u_{y}-v_{x} w_{y}+f D_{z x} \\
& +\left(\bar{u}^{\prime} \bar{w}_{z}^{\prime}-\bar{w}^{\prime} w_{z}^{\prime}\right)_{z}=f\left(\frac{\partial v}{\partial z}-\frac{\partial v_{g}}{\partial z}\right)
\end{aligned}
$$

where $\eta$ and $D_{z x}$ are the vorticity and divergence in $(x, z)$-plane and other symbols are conventional. Here the generalized terminology "solenoidal circulation" is used for the circulation to be generated by the unbalance between motion 

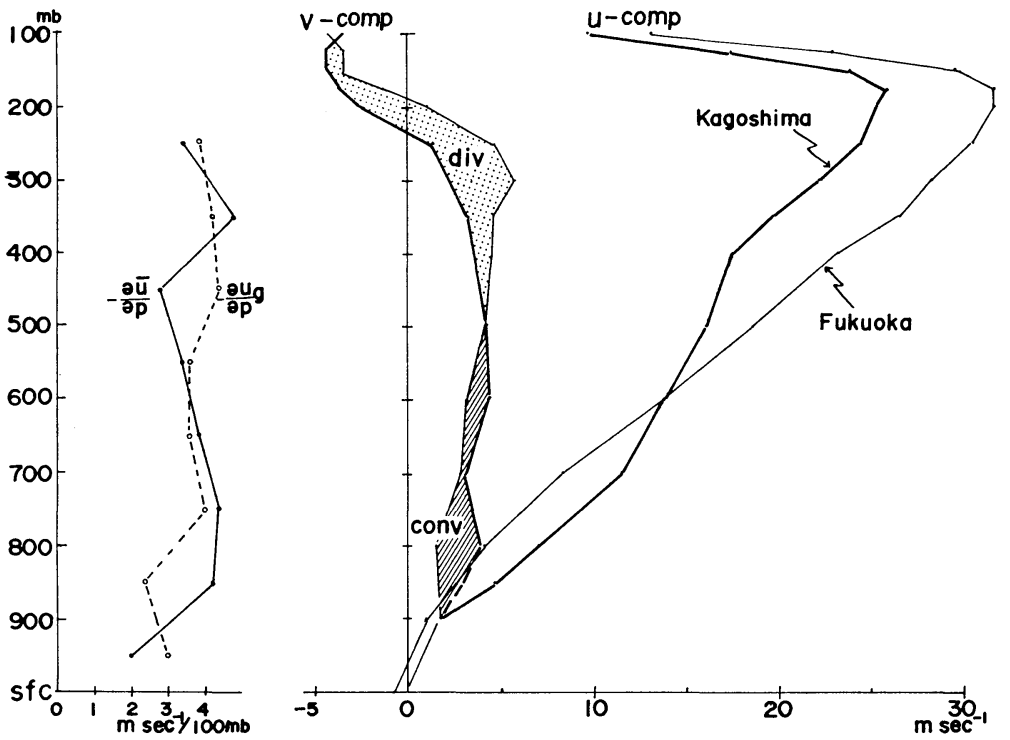

Fig. 14. Monthly mean wind profiles of June 1970 at Fukuoka (heavy line) and Kagoshima (thin line) for $u$ - and $v$ component. Vertical shear of actual wind $\left(-\frac{\partial u}{\partial p}\right.$, solid line) and geostrophic wind $\left(-\frac{\partial u_{g}}{\partial p}\right.$, dashed line $)$ are given on the left.

field and mass field. The expected circulo-genesis is given in Fig. 13 which is the same as the model given by Matsumoto and Ninomiya (1971).

The downdraft branch of the generated circulation will give rise to the warm and dry air and, as a matter of fact, we do observe it. However the resulted temperature gradient is yet much less to balance with the preexisting vertical wind shear. In this respect the motion field should be regarded to have the primary effect. Once the unbalanced excess momentum be produced by some conditions, an indirect circulation will follow to adjust the mass field with the motion field. If on the contrary the mass field is specified a priori, a direct circulation will be generated. The atmospheric function of geostrophic adjustment has an essential role in the large scale motions but not in the smaller scale motions.

The proposed relationship between unbalanced field and solenoidal circulation can be seen in the monthly mean field. In the Far East, the so-called "Baiu" frontal activity prevails during June, when precipitations take place quite frequently and we often find low-level jets (westerly in most of the cases) particularly associated with convective type heavy rainfalls.
The monthly mean fields of June 1970 are analysed in the meridional cross section along $130^{\circ} \mathrm{E}$. The wind profiles at Fukuoka (47807) and Kagoshima (47827) are shown in the right hand side of Fig. 14. Kagoshima is located only about $220 \mathrm{~km}$ to the south of Fukuoka, but there are considerable differences in wind profile both of zonal and meridional component. The fact that southerly wind in the troposphere is stronger in Kagoshima below $500 \mathrm{mb}$ level and weaker above it and, therefore, convergence in the lower troposphere and divergence in the upper troposphere should be expected since averaged values generally show zonal uniformity, provides a favorable condition to maintain convective activities. Consequently development of low-level jet stream is very likely to be realized. The wind profile of zonal component shows an indication of momentum increase in the lower layers at Kagoshima. The concentration is not conspicuous because of averaging procedure over one month period, but still we can define climatological westerly low-level jet at about $700 \mathrm{mb}$ level.

Now let us examine the thermal wind balance. The vertical shear of geostrophic wind and actual wind (both zonal component) are computed for 

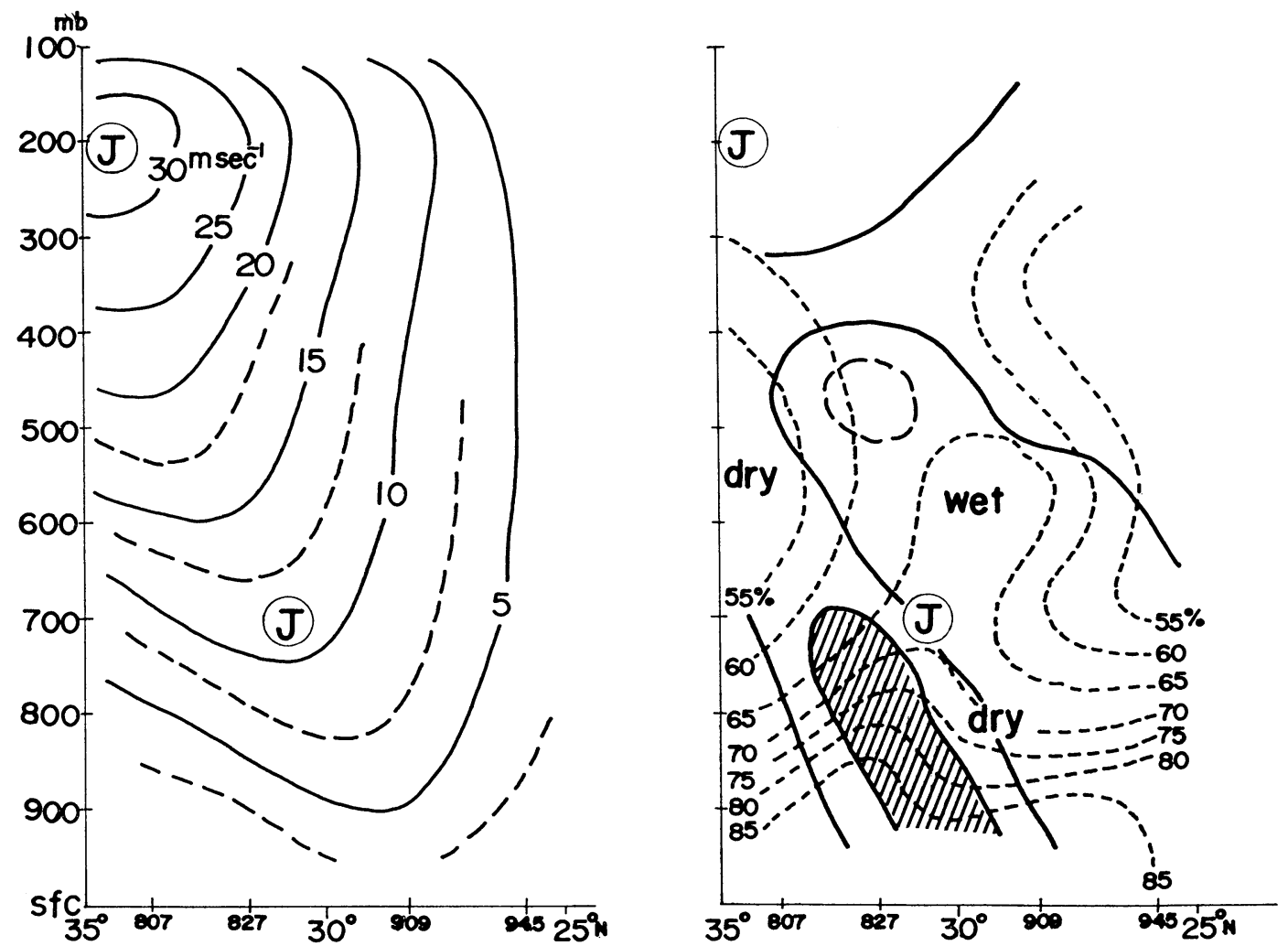

Fig. 15. Vertical cross section of wind speed (left) and relative humidity (right) both for monthly mean field of June 1970. Difference between actual wind and geostrophic wind are entered by dotted line and thinner solid line respectively.

the region between Kagoshima and Fukuoka and presented in the left hand side of Fig. 14. Comparing these two, we find large differences in the layers between $800 \mathrm{mb}$ and $900 \mathrm{mb}$ and between $400 \mathrm{mb}$ and $500 \mathrm{mb}$ and

$$
\begin{aligned}
& \frac{\partial \bar{u}}{\partial z}>\frac{\partial u_{g}}{\partial z} \quad \text { below the jet level, } \\
& \frac{\partial \bar{u}}{\partial z}<\frac{\partial u_{g}}{\partial z} \text { above the jet level, }
\end{aligned}
$$

where $\bar{u}$ and $u_{g}$ are the monthly mean zonal component wind averaged between Kagoshima and Fukuoka and corresponding geostrophic wind respectively. The unbalanced situation obtained here is exactly the same as an individual case mentioned above.

Meridional cross sections of monthly mean field along $130^{\circ} \mathrm{E}$ are given in Fig. 15. The left hand side figure is for the monthly mean scaler wind velocity. The locations of upper and lower jet are entered by bold letter " $\mathrm{J}$ ". In the right hand side figure are presented monthly mean relative humidity (dashed line), unbalanced wind shear (heavy line) and jet location. Shaded area shows positive unbalance with the value greater than $1 \mathrm{~m} \mathrm{sec}^{-1} / 100 \mathrm{mb}$. Of particular interest here is the relative humidity distribution in the proximity of low-level jet. Dry areas are found in the lower right and the upper left of the climatological low-level jet, while it is considerably wet in the upper right. The configuration of those dry and wet airs is in a good agreement with the proposed solenoidal circulation generated by positive and negative unbalaned wind shear below and above the low-level jet core respectively.

\section{Discussion}

In most of the cases, the low-level jet is in geostrophically unbalanced situation. Studies on the geostrophic adjustment procedure show that the motion field is adjusted with the mass field if the scale of motion is larger and the mass field tends to be adjusted with the motion field if the 
scale of phenomena is smaller. Since the lowlevel jet studied here is super-geostrophic, it may be safely infered that the concentration in the motion field has the primary effect and the indirect type of circulation is induced to adjust the mass field. The indirect circulation causes an increase of potential energy at the expense of kinetic energy. Therefore kinetic energy has to be supplied from somewhere. One possibility is that the kinetic energy of this type of motion is converted from convective scale motion through counter gradient momentum transfer. There is another possibility of supply in a form of systematic flow from higher kinetic energy region in the atmosphere. In this paper, the latter type of transport is suggested, although the mechanism of downward transport is not known yet.

The discussion made in previous sections are derived from analyses of a single case study at one stage of development. There could be some other transient situations in the process of atmospheric adjustment. Anyway it is quite important to recognize that the atmospheric condition in case of severe phenomena of sub-synoptic scale is highly unbalanced.

\section{Acknowledgements}

Analyses presented here are mostly based on the data of Severe Rainfall Research Project observation published by Meteorological Research
Institute. The author expresses thanks to $\mathrm{Mr}$. S. Taga, Director, Fukuoka District Meteorological Observatory for his encouragements. Thanks are also due to Miss $\mathrm{H}$. Nishimura who drafted figures.

\section{References}

Beebe, R.G. and F.C. Bates, 1955: A mechanism for assisting in the release of convective instability Mon. Wea. Rev., 83, 1-10.

Matsumoto, S. and K. Ninomiya, 1971: On the mesoscale and medium scale structure of a cold front and the relevant vertical circulation. Prof. Syono Memorial Volume (to be published).

Matsumoto, S., T. Fujita and T. Asai, 1962: Analysis of low-level jet associated with the heavy rain observed over Japan, 24-31, June, 1961. Tenki, 9, 213-221.

Matsumoto, S., K. Ninomiya and T. Akiyama, 1967: Cumulus activities in relation to the mesoscale convergence field. J. Meteor. Soc. Japan, 45, 292305.

Matsumoto, S., S. Yoshizumi and M. Takeuchi, 1970: On the structure of the Baiu front and the associated intermediate-scale disturbances in the lower atmosphere. J. Meteor. Soc. Japan, 48, 479-491.

Matsumoto, S., K. Ninomiya and S. Yoshizumi, 1971: Characteristic features of "Baiu front" associated with heavy rainfall. J. Meteor. Soc. Japan, 49, 267-281.

Wexler, H., 1961: A boundary layer interpretation of the low-level jet. Tellus, 13, 368-378.

\title{
大雨に伴なう非均合いの下層ジェットとソレノイド循環
}

\author{
松 本 誠 -
(福岡管区気像台)
}

1970年 7 月 7 日九州に顕著な南風下層ジェットが現われこのジェット軸の西側で大雨が降った。ジェット核周辺 の中規模の温度場構造は，風の場に調節された徴候を間接的に示しているが，非常に非均合いの状態にあることがわ かる。ジェット核の下㞗の染側に現われた暖かい空気は乾燥しているという特徵があり，恐らく間援循環により生成 されたものであろう。

1970年 6 月の月平均値についても，下部対流圈の風・気温・相対湿度場に同様な関係が成立つことが判明した。 